\title{
Retraction Note: Spatiotemporal evolution characteristics of extreme rainfall based on intelligent recognition and evaluation of music teaching effect in colleges and universities
}

\author{
Dan $\mathrm{He}^{1,2} \cdot \mathrm{Na} \mathrm{Luo}^{1}$
}

Published online: 17 November 2021

(c) Saudi Society for Geosciences 2021

Retraction Note: Arabian Journal of Geosciences (2021) 14: 1571

https://doi.org/10.1007/s12517-021-07929-z

The Editor-in-Chief and the Publisher have retracted this article because the content of this article is nonsensical. The peer review process was not carried out in accordance with the Publisher's peer review policy. Author Na Luo has not responded to correspondence regarding this retraction. The Publisher has not been able to obtain a current email address for author Dan He.

The original article can be found online at https://doi.org/10.1007/ s12517-021-07929-z.

$\mathrm{Na}$ Luo

luona13809237@sina.com

1 School of Arts, Hubei University of Education, Wuhan 430205, China

2 Dongbang Culture University, Seoul 100-744, Republic of Korea 